\title{
MANAGEMENT OF THE PHANOM-SURIN ARCHAEOLOGICAL SITE IN THAILAND: CONCEPT, POLICIES AND PRACTICES
}

\author{
Abhirada Komoot ${ }^{*}$ \\ University of Western Australia, 35 Stirling Highway, Perth WA 6009 Australia \\ Email: abhirada.k@gmail.com
}

Published online: 30 July 2021

To cite this article: Komoot, A. 2021. Management of the Phanom-Surin archaeological site in Thailand: Concept, policies and practices. International Journal of Asia Pacific Studies 17 (2): 75-105. https://doi.org/10.21315/ ijaps2021.17.2.4

To link to this article: https://doi.org/10.21315/ijaps2021.17.2.4

\begin{abstract}
The Phanom-Surin (PNS) archaeological site contains the remains of a sewn-plank vessel that is dated to the 9th century CE and discovered in Thailand's mangrove swamp. As the only accessible sewn-plank vessel archaeology in the world, it provides research opportunities and potential for collaboration between heritage stakeholders. Preservation of the site within its context is crucial. Throughout this article, I will explain the importance of the PNS site management and its context based on my experience. The fuller understanding of the PNS site relies much on the information to be extracted from the materials and contexts. This article therefore encourages the preservation and management of the site within the original context. There are several relevant international guidelines for heritage and environmental management, such as the World Heritage Operational Guidelines, the Annex of the UNESCO (United Nations Educational, Scientific and Cultural Organization) 2001 Convention and the technical Ramsar Convention, all of which can help develop domestic framework and practices. This article aims to draw public and government attention towards the PNS site, and discusses concepts, policies and practices relating to the site.
\end{abstract}

Keywords: Phanom-Surin vessel, Thailand, maritime archaeology and history, Indian Ocean World, shipwreck management 


\section{INTRODUCTION}

This article discusses concepts of heritage and its management practice in Thailand that can potentially affect the future of the Phanom-Surin (PNS) archaeological site. It discusses the issues and significance surrounding the site, and aims to advance the knowledge of better maritime site management in Thailand.

In the field of heritage management, one of the fundamental questions is often "why should the site be managed and protected?" The PNS site demonstrates long-distance connectivity in the late 1st millennium CE Indian Ocean World. The technology used to build the vessel, its antiquity, rarity and site location all justify focussed expert investigation, carefully structured professional management, absolute comprehensive protection and careful promotion for public education. The PNS site management must ensure the benefits for the present and future use and appreciation.

Scientific research is necessary if we are to sustainably manage the maritime heritage of the PNS site. Collaboration benefits many disciplines. Theoretical and legal methods discussed here aim at providing a conceptual framework for maritime archaeological practice and heritage management in Thailand, especially since many archaeological sites including the PNS have been accidentally found and disturbed prior to systematic investigation. This necessitates collaborative frameworks between the Fine Arts Department (or FAD) of Thailand and other institutions (i.e. research institutions and universities). The PNS site case potentially unlocks ways of researching and managing maritime archaeology in Thailand and, it is hoped, will be a guiding protocol for historical shipwreck protection for the future.

\section{The PNS Archaeological Site and Its Context}

The PNS vessel is buried in a mangrove swamp in Samut Sakhon province, which is approximately $40 \mathrm{~km}$ southwest of Bangkok. Figure 1 shows the location of the PNS site sitting between two major rivers, approximately $13 \mathrm{~km}$ from Tha Chin River to the west and $20 \mathrm{~km}$ from Chao Phraya River on the east. A total area of $6,400 \mathrm{sq} \mathrm{m}$ (4 rai) has been donated by the landowners ${ }^{1}$ for the PNS project. Approximately $750 \mathrm{sq} \mathrm{m}(16 \times 46 \mathrm{~m})$ was defined as the archaeological assemblage during the 2013-2015 field seasons (as shown in Figure 2) and was extended at the southern end for further testing in 2020. The results of the excavations show the assemblage of a large 
amount of structural timbers and small unidentified wooden artefacts, ceramics of diverse origins, a metal bowl and various kinds of organic materials (Jumprom 2019).

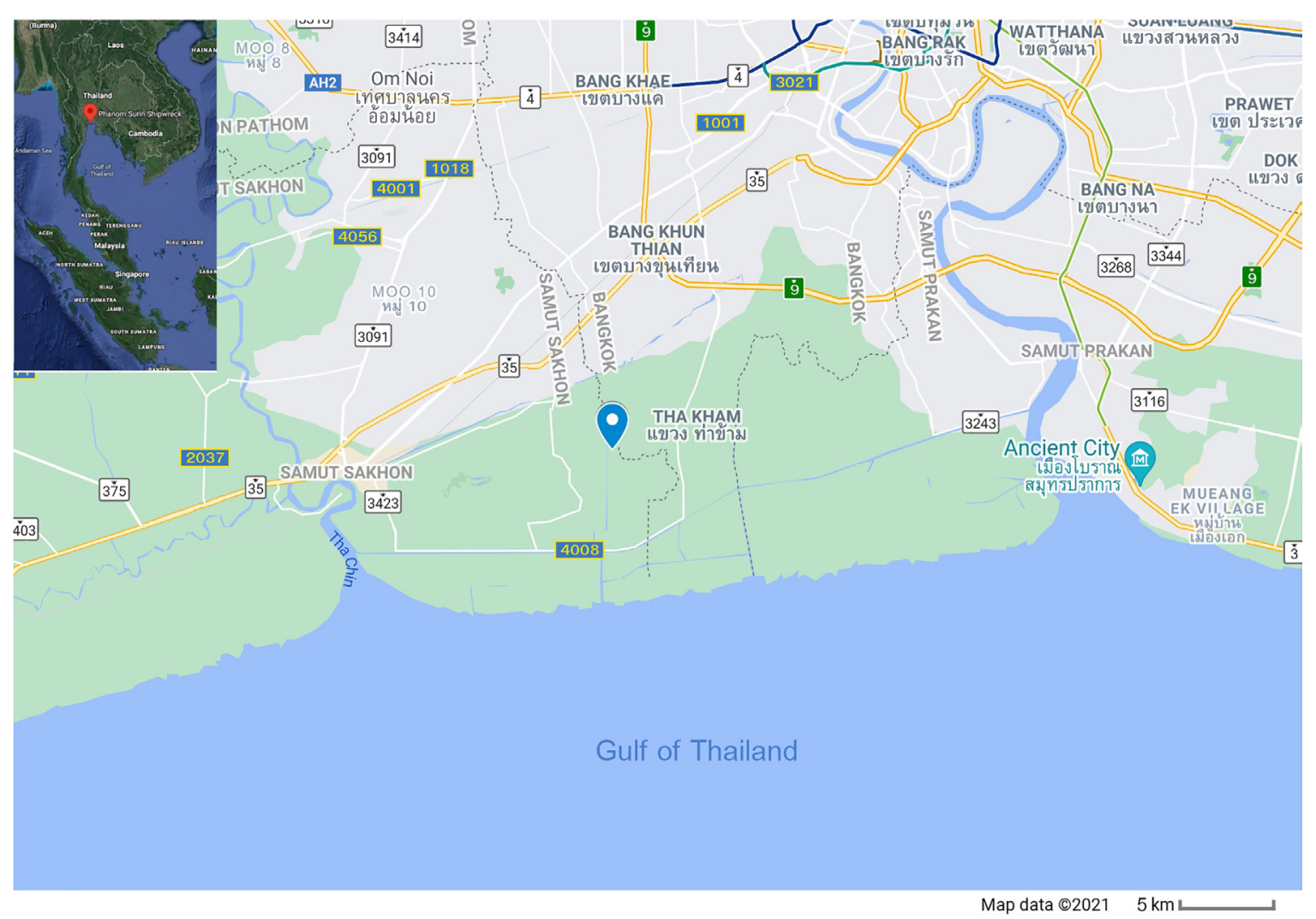

Figure 1: Location of the PNS shipwreck site.

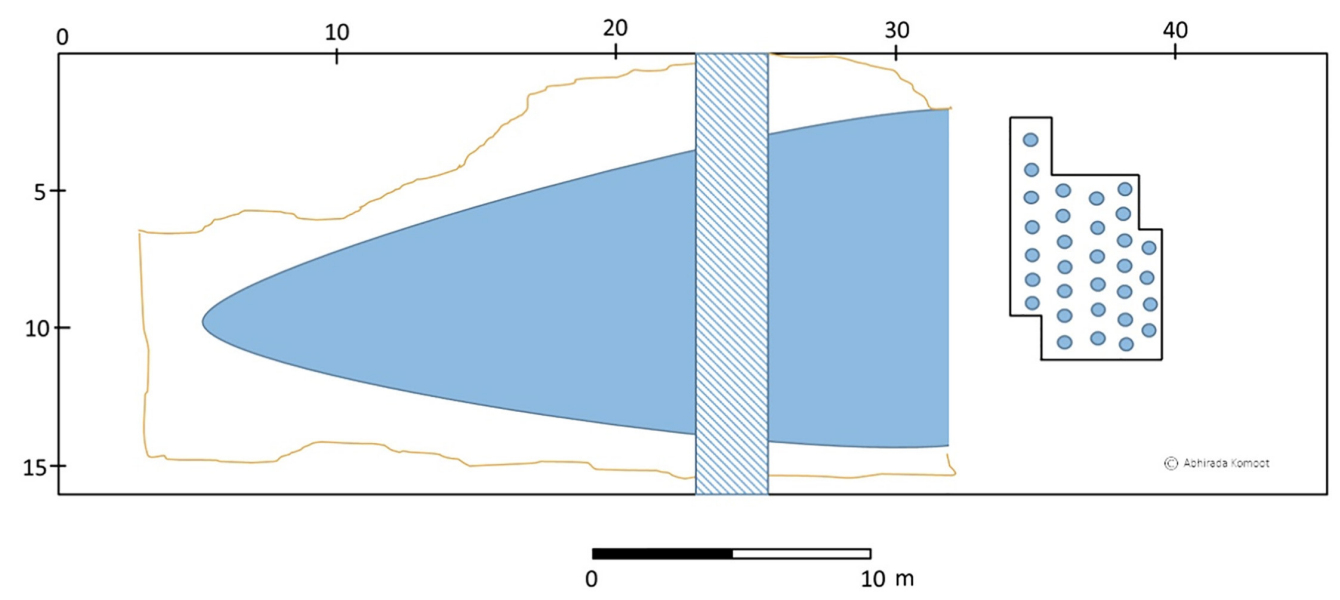

Figure 2: The PNS excavation plan from 2013 to 2015 (reproduced from Dacha Phongthai's drawing). 
Overall, the PNS shipwreck site was well preserved under wet anaerobic conditions for over one thousand years. The site thus holds a great deal of information about the vessel structure, its history as well as the history of the environment. The site thus should be considered in a long-term plan to be preserved within its original context as it has great potential to enhance our knowledge of the Indian Ocean World's maritime history in the late 1st millennium CE. It can prove or disprove our prior knowledge about sewn-plank shipbuilding technology and cultural connectivity of that period. It is also valuable for investigating the environmental context. Within the ecologically dynamic area between historic tidal land and shallow water, it holds key information for better understanding of environmental changes and social interactions between land and sea peoples. To gain full knowledge of the context of the PNS site, conservation and research are required.

The PNS' locational context contributes to better understanding of terrestrial-maritime connections, which adds valuable meaning to the site. It helps us reconstruct the past and to find out how the area was used or how changes in landscape have impacted human behaviour. In the 9th century, this site was uninhabitable. The location of the PNS site in the Lower Central Plain of Thailand, approximately $8 \mathrm{~km}$ from the present shoreline (as shown in Figure 1), is suggested to be below the historic shoreline (Hutangkura 2014; Ploymukda 2016). Ancient settlements of the Dvaravati Kingdom (6th to 11th centuries) were only limited on the land above the belt of ancient shorelines (Songtham et al. 2015) with the centre of the Kingdom in Nakhon Pathom province (Wales 1969; Dupont 2006). The Tha Chin river was the main channel that linked the Dvaravati kingdom with the wider maritime network at the time (as shown in Figures 1 and 3) (the future study of ancient river courses will be useful to elaborate this connection). Interestingly, the area at the head of the Gulf of Thailand was not mentioned in the historical Arabic accounts of the 9th century, but it was known to the Chinese since the Han period (Briggs 1950; Zhaoming 2014). The PNS site may therefore help highlight the role of mainland Southeast Asia in the history of ancient maritime trade and contact.

Archaeologically speaking, the PNS shipbuilding technology is substantially different from the Southeast Asian lashed-lug technology. The PNS shipwreck exhibits sewn-plank technology: the planks are fastened with fibre cordage over wadding both inside and outside of the hull. The sewing pattern is a continuous cross-stitch alternating with vertical lines (as shown in Figure 4). No blind dowels were used to hold the planks in place. 


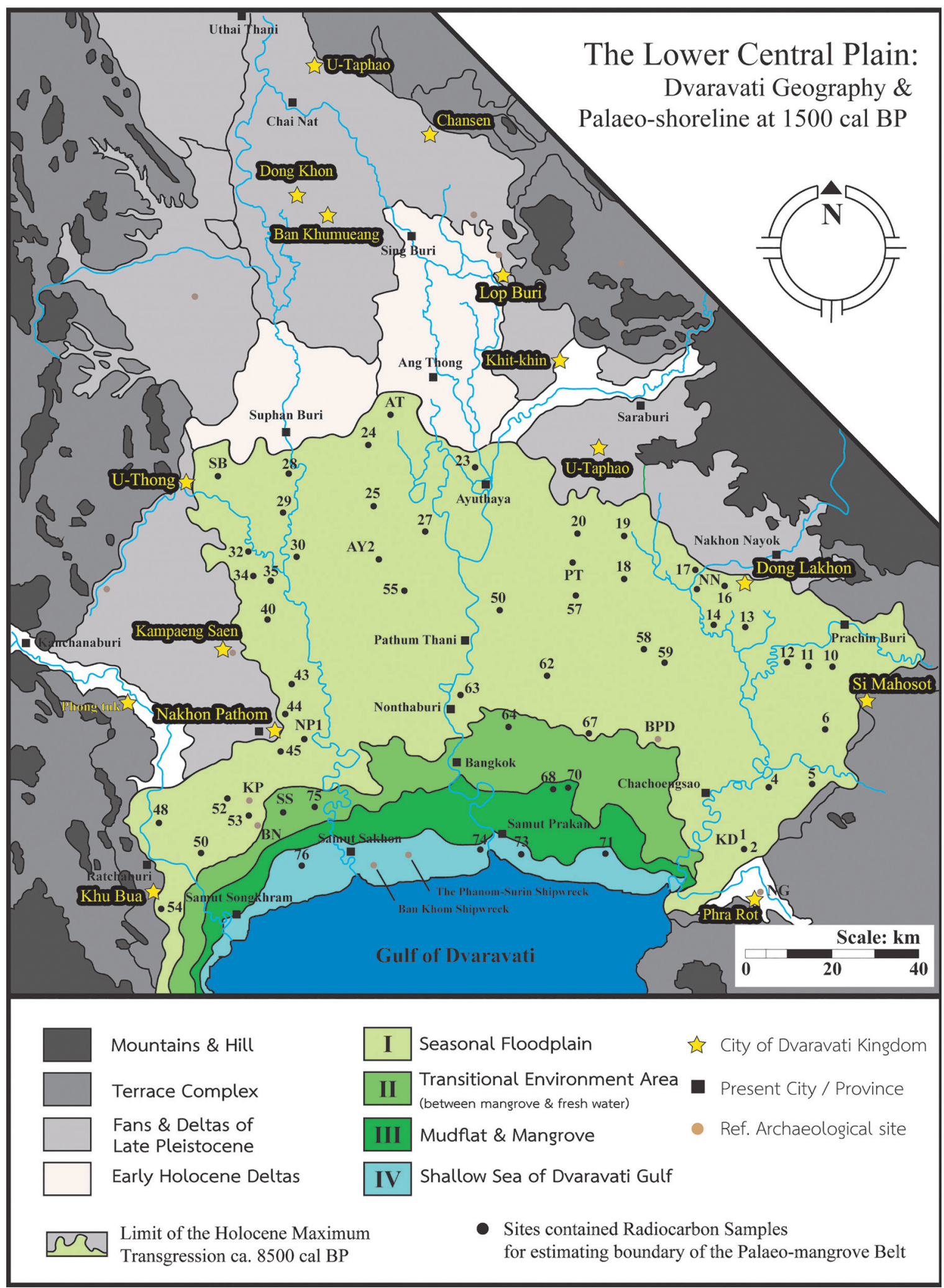

Figure 3: A reconstructed map of the phytography and locations of key Dvaravati cities (courtesy of Dr. Trongjai Hutangkura). 
The technology resembles the western Indian Ocean tradition. In Southeast Asia, lashed-lug vessels were developed in the 1st millennium CE, overlapping with the PNS vessel and distributed throughout the region (Lacsina 2016; Manguin 2019; Mochtar 2018). This technology had lugs on the inside surfaces of the carved planks (as shown in Figure 5b). Inboard structures, such as the frames, were lashed onto the lugs with Arenga cordage (as shown in Figure 5a). The Southeast Asian shipwrights lashed structures with the inboard lugs by making individual patterns (i.e. loops or braid). The planks were generally fastened with wooden edge-dowels (as shown in Figure 6b). For most lashed-lug vessels of early dates (e.g. Kuan Luk Pad, Potian and Punjuhaljo), individual stitching was incorporated to aid dowelled planking (as shown in Figure 7). The individual stitching pattern in the lashed-lug vessels later disappeared as demonstrated in the Cirebon shipwreck (Liebner 2014: 251). Edge dowelling however is a common practice in Southeast Asian shipbuilding until today.
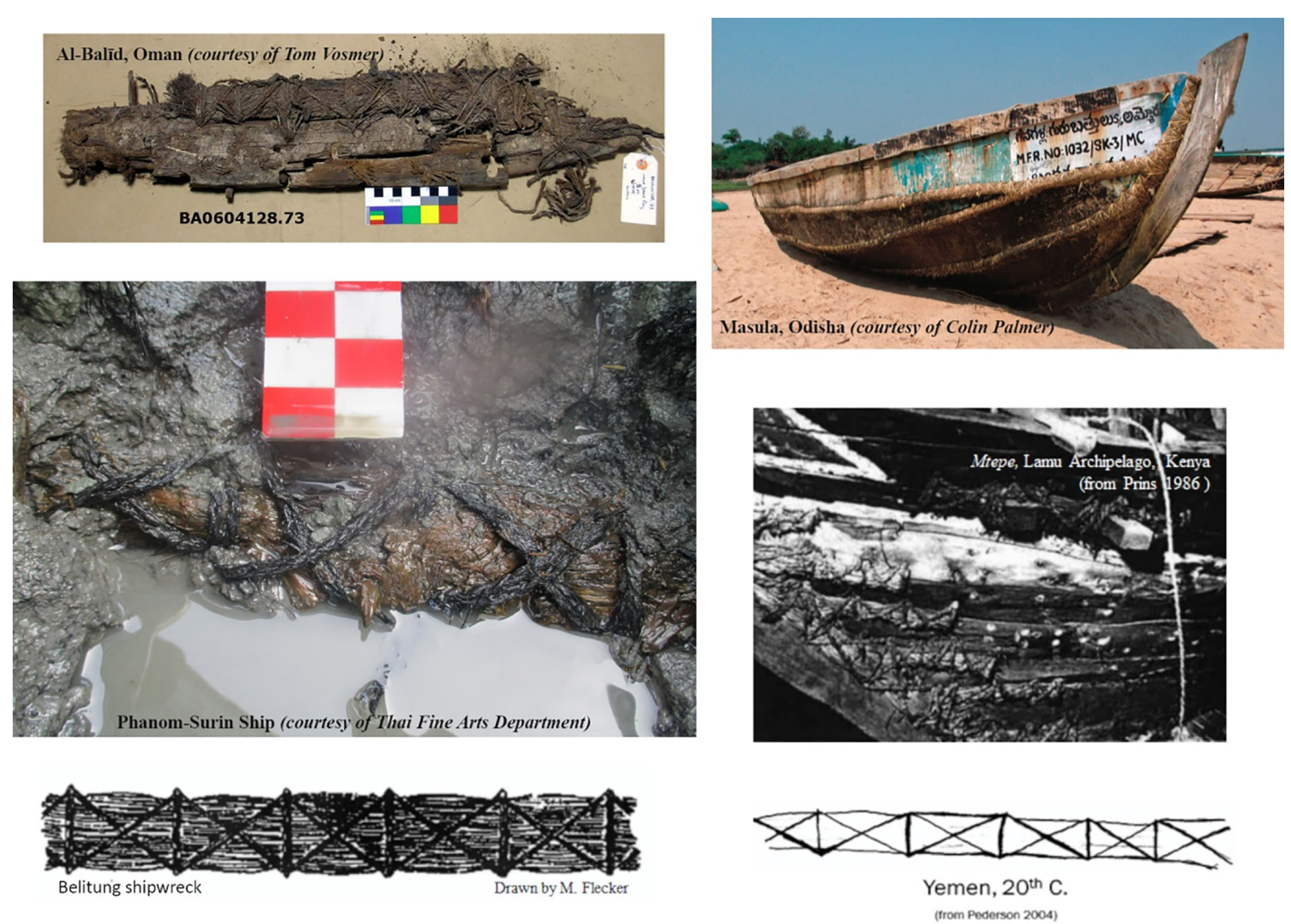

Figure 4: Sewn-plank vessels in the Indian Ocean. 

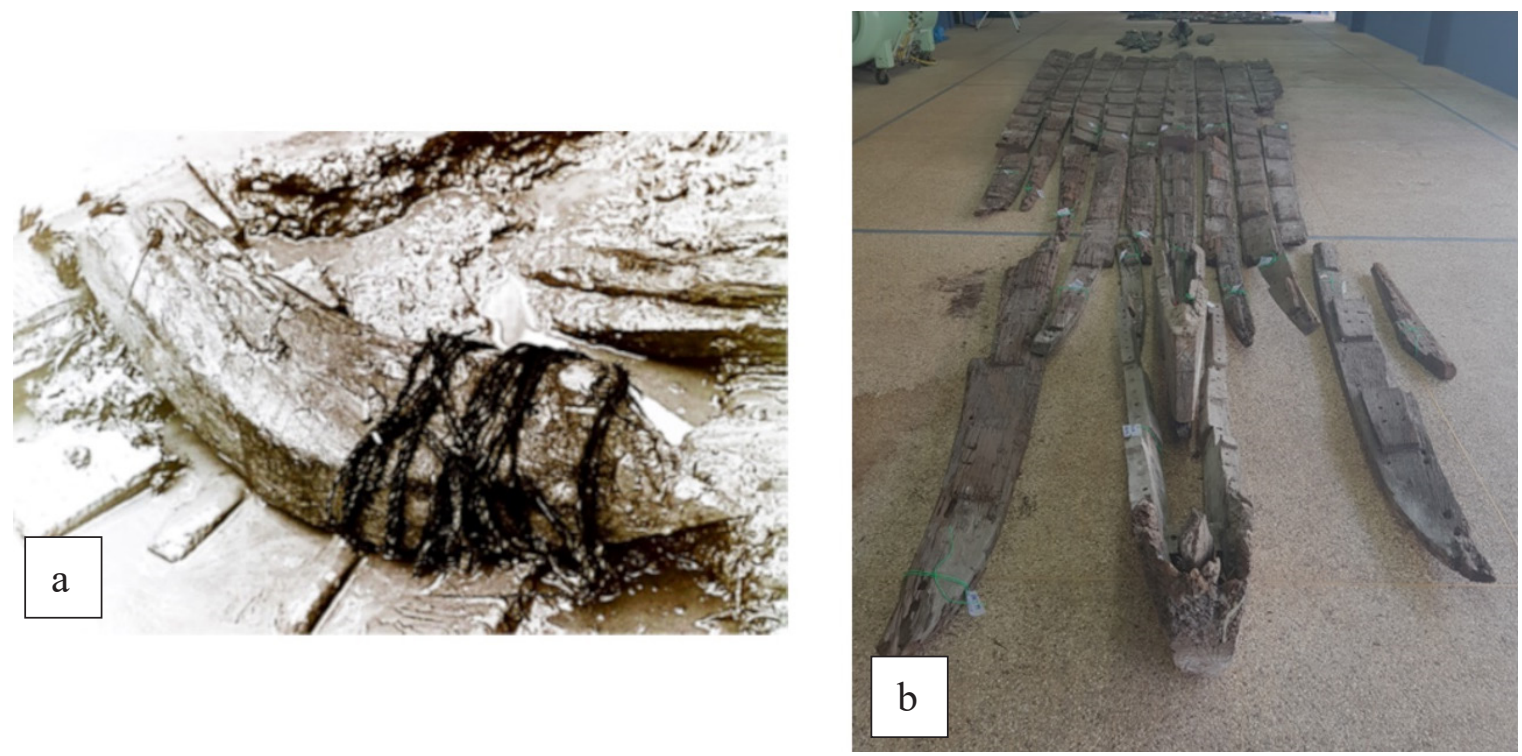

Figure 5: (a) Frame lashed with Arenga cordage at Butuan Boat 2 (photo courtesy of National Museum of the Philippines) and (b) Lashed-lug plank remains from Ban Klong Yuan site, Thailand (photo courtesy of Thai Underwater Archaeology Division).

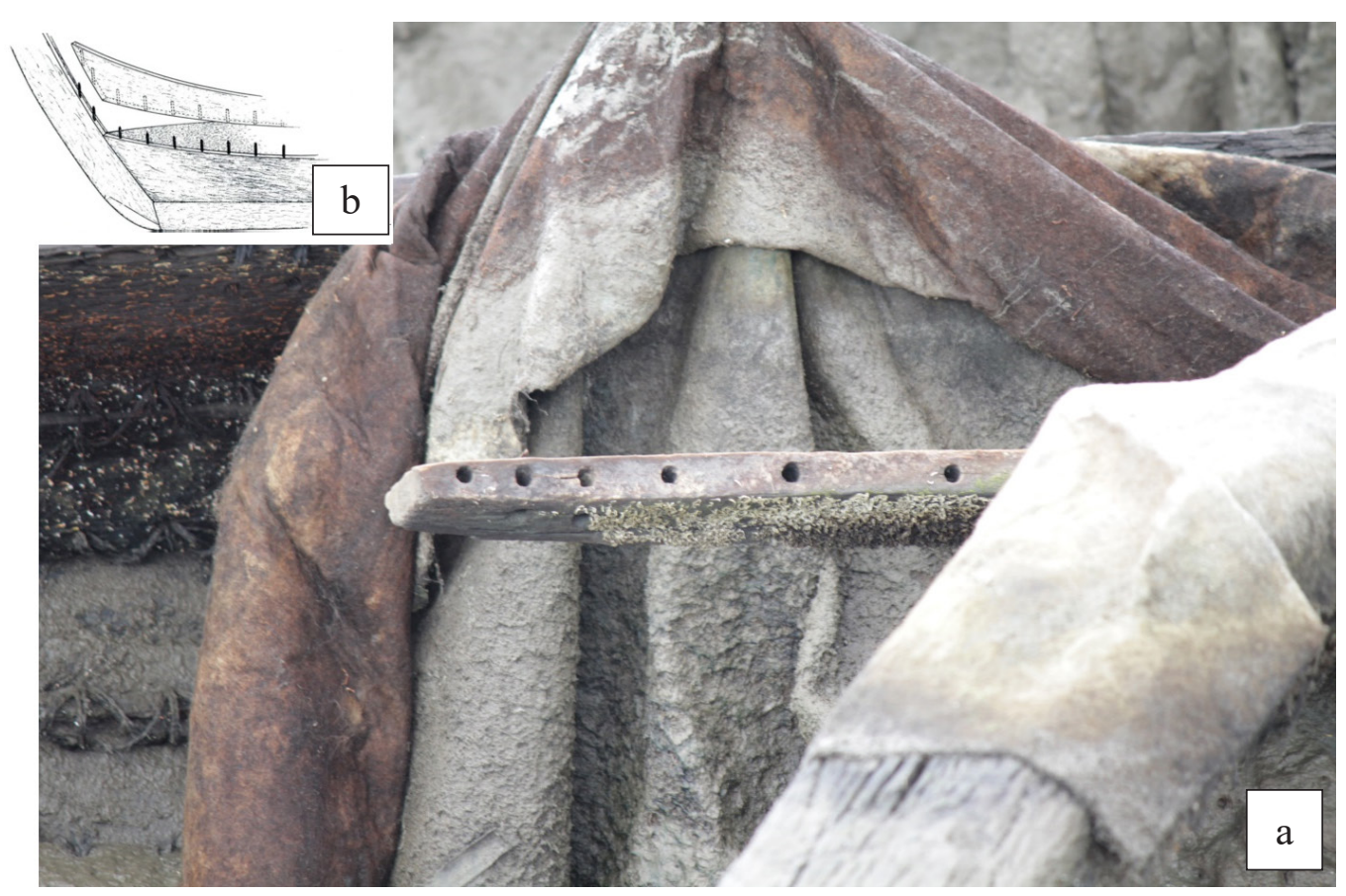

Figure 6: (a) Timber with dowelling holes at the PNS site (photo courtesy of Thai Fine Arts Department) and (b) Edge-dowelled planks of Javanese perahus. Source: Burningham (1989) 


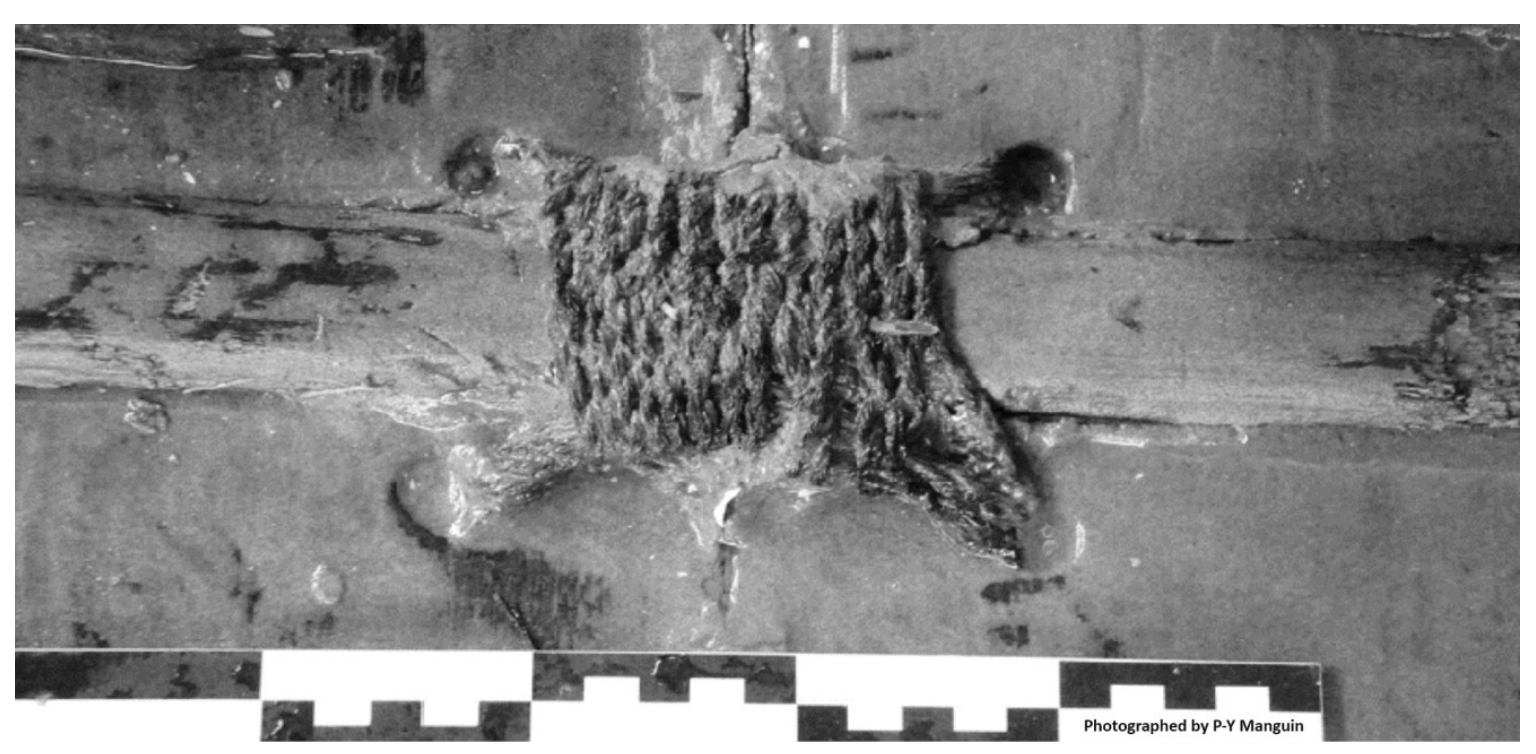

Figure 7: Stitches on lashed-lug (photo courtesy of P.-Y. Manguin).

Although these two techniques of individual stitching and edge dowelling seem to be significantly different, the findings at the PNS suggest a certain degree of connection. Timbers with dowel holes on the edge were found on the PNS site (as shown in Figure 6a) but it cannot be ascertained at this stage whether the timbers were part of the PNS structure. If so, how did they fit with the sewn-plank method? In the normal sewn planks, holes are drilled on the surface near the edge, but the dowel holes on the plank edge are common in lashed-lug technique. So far, no actual dowels have been found in the PNS timbers.

Approximately $10 \mathrm{~km}$ from the PNS site, lashed-lug boat remains of Dvaravati period (6th to 11th centuries CE) were found in Ban Khom district, Samut Sakhon province (Ban Khom Shipwreck 1998) (as shown in Figure 3). In the intra-regional network, lashed-lug technology has been identified on the Southeast Asian littorals (as shown in Figure 8). The co-existence of these two shipbuilding methods strongly suggests the PNS shipmasters could also have used the local route as a channel of communication with the Dvaravati ancient kingdom. Considering the distribution of the lashed-lug vessels, this interrelation is part of a cultural network with the neighbouring polities such as Champa in the Mekong River basin and Sriwijaya in the Insular Southeast Asia.

Recent research has found a strong link between the PNS site and the wider Indian Ocean. The PNS vessel has revealed vessel building technology that is similar to those of the Indian Ocean tradition, but the materials were from Southeast Asia (Jumprom 2019). Yet, along with Southeast Asian 
timbers, Arenga cordage were used in the PNS vessel construction. This type of fibre cordage is Southeast Asian in origin and was used for shipbuilding in the region since at least the 4th century ( $\mathrm{Li} 1979$; Manguin 1993). The historical Arabic accounts described Arab shipwrights who travelled to a places with resources (i.e. Lakshedweep or Maldive islands) to build their vessels (Mackintosh-Smith et al. 2014: 109). It can be assumed that the shipwrights might have applied the same practice to the PNS vessel although no record has been located yet. These pieces of information may indicate the PNS was built or substantially repaired in Southeast Asia by Indian Ocean shipwrights (Komoot, forthcoming). This however is a topic that has been least developed in the archaeology of Proto-historic Thailand and the whole Indian Ocean World. More research is thus needed to support this notion.

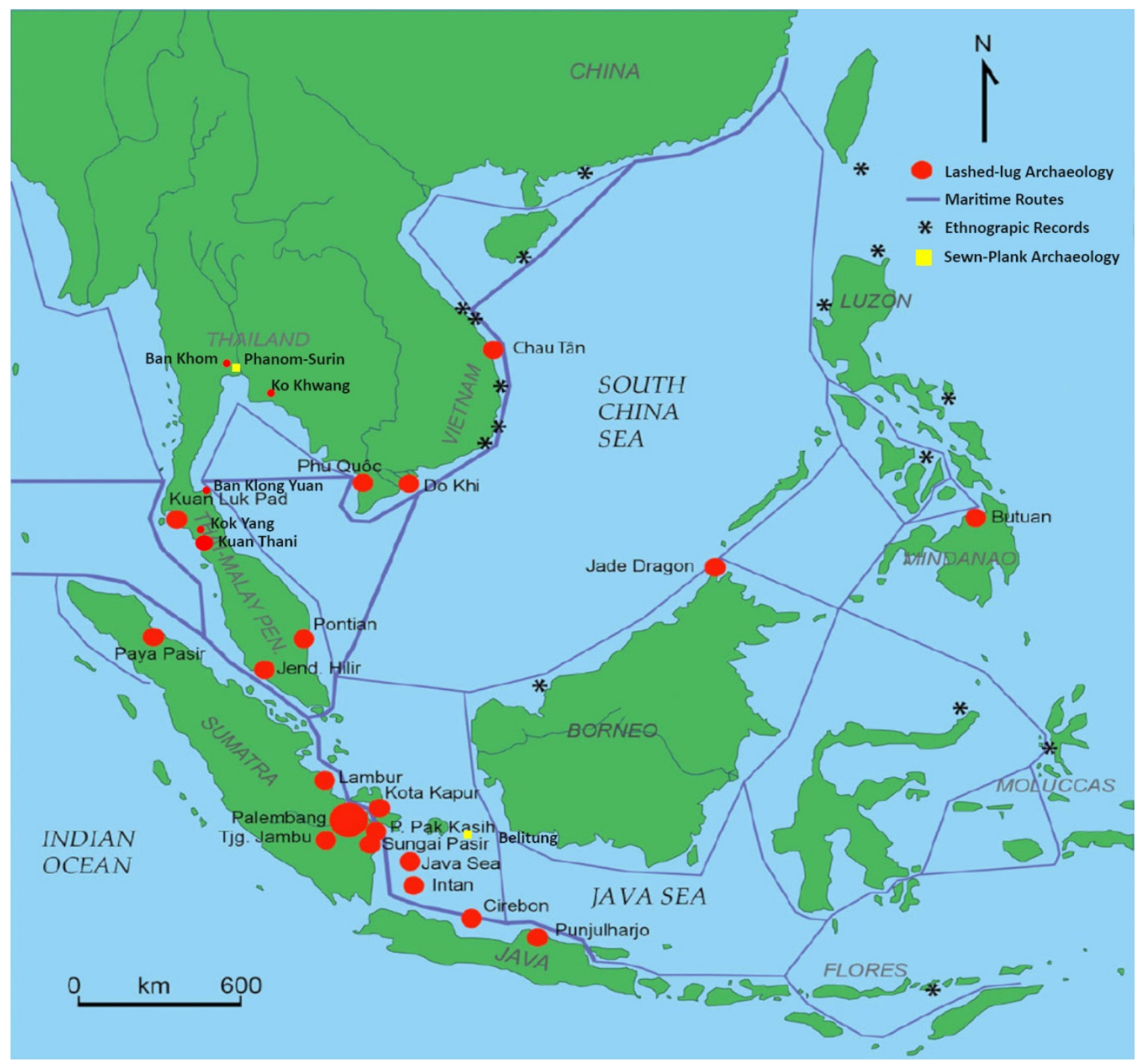

Figure 8: Map of vessel archaeology in Southeast Asia (modified from Manguin 2019). 
There is also evidence of site abandonment and historic salvage. Non-structural timbers off the starboard side suggest they were used as leverage to lift the hull while attempting to salvage or rescue the vessel (as shown in Figure 9). The PNS vessel lists to the port side where the sewn hull is laid flat and its hood ends detached from the stem. The starboard hull keeps the shape, but its sheer strake seems to be missing and was perhaps reused elsewhere. Was the vessel abandoned rather than wrecked? If so, why? These questions are important to explain why there is only a small amount of cargo left on the PNS vessel, compared to those of the Belitung vessel, another sewn-plank vessel that was wrecked in Indonesian waters; it was dated in the same period and built with the same technology (Flecker 2000; Krahl and Effeny 2010; Chong and Murphy 2017).

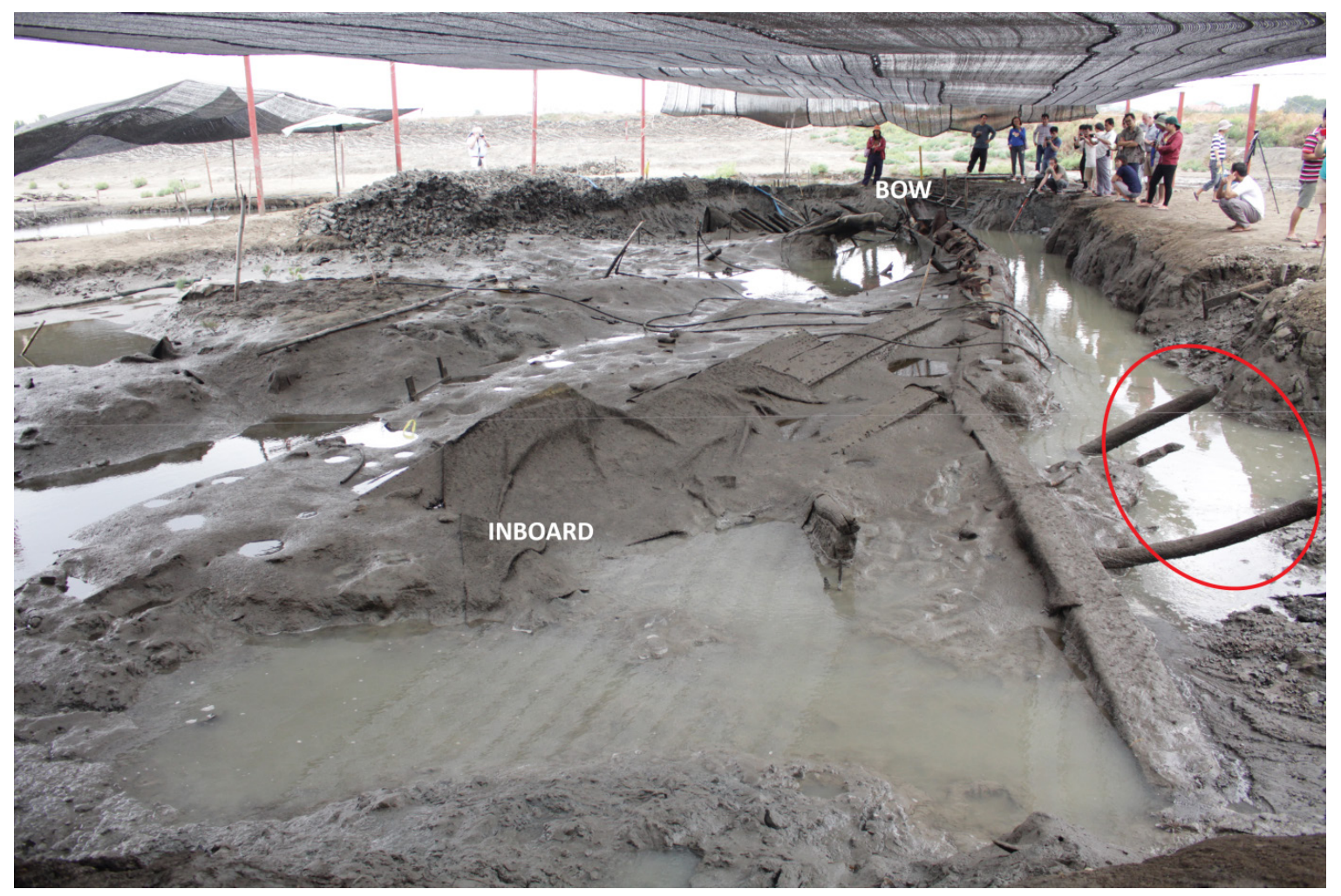

Figure 9: Non-structural timbers used while attempting to salvage or rescue the vessel (photo courtesy of the Thai Fine Arts Department; it was modified for the purposes of this article).

Additionally, the archaeological site is critical for conservation and environmental science. The PNS comprises organic materials, including wooden structures with sewing cordage and wadding. However, organic artefacts like seeds, animal bones, leather and many other items have also been discovered at the site; they have been well preserved, thanks to the 
water-saturated conditions. Interestingly, the preservation of these materials differ according to dry and wet conditions (as shown in Figure 10). Keen documentation of the environmental context is necessary, such as the type of material, $\mathrm{pH}$ level, temperature, oxygen content and human-induced activities, and how they impact the preservation of the artefacts. For the PNS project, a conservation plan is strategically proposed along with the excavation plan in 2021. Conservators should be on site to provide practical information and ensure the integrity of the project throughout the excavation.

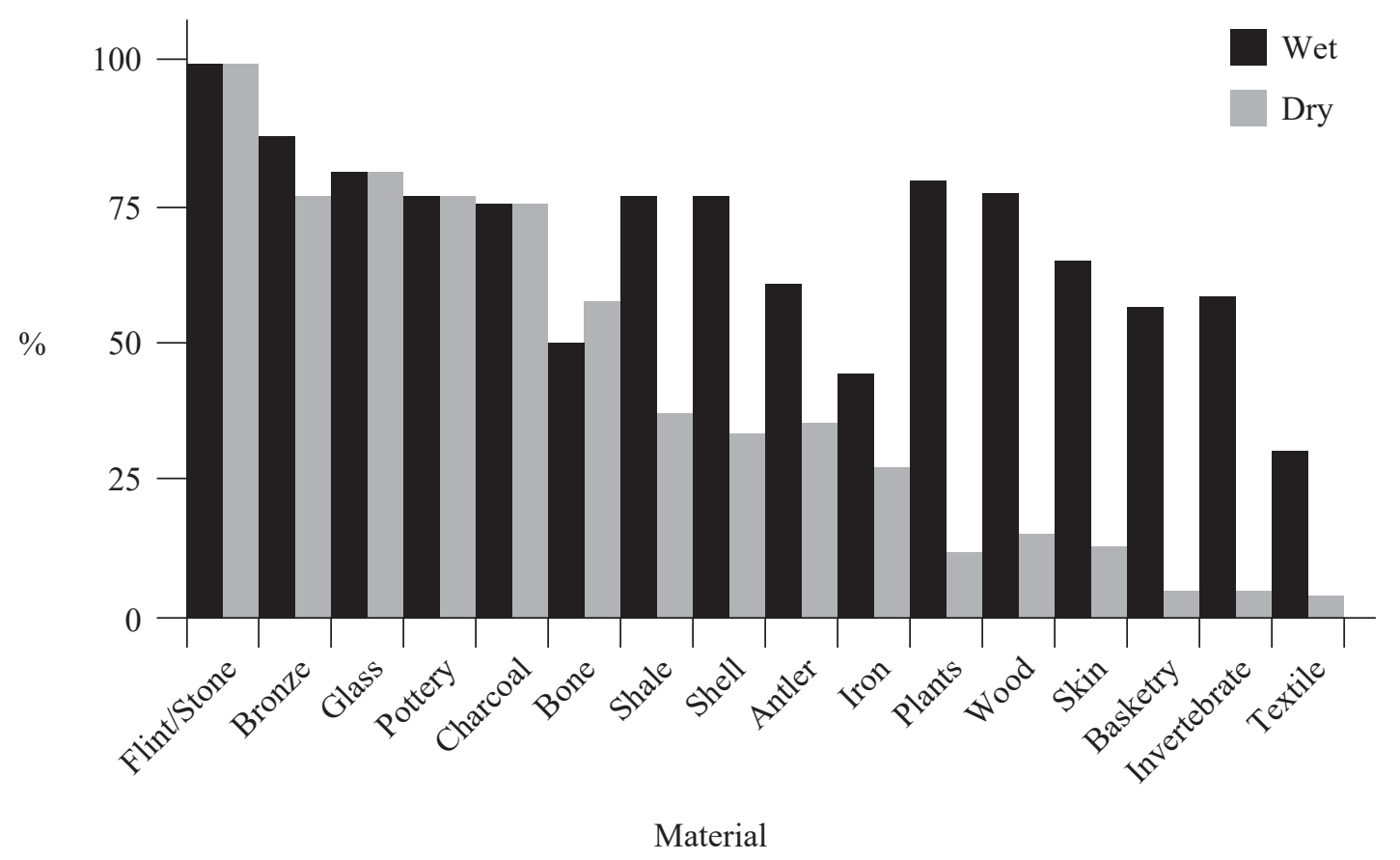

Figure 10: Preservation of different materials in wet and dry conditions. Source: Menotti (2012: 15)

\section{SIGNIFICANCE}

The PNS site is best preserved at its original location to maintain the value of archaeological and environmental records. Its excellent preservation serves as a natural archive and valuable scientific reference for different scholars and interest groups, and will be discussed in the following section, along with its political and economic significance. 


\section{Scientific Significance}

The largest waterlogged wooden vessel ever discovered in Thailand, the PNS vessel enjoys a great advantage of being protected by the Thai government and is available for detailed excavation when proper resources are provided. Given the large working area in the challenging environment, the collaborative team working on the PNS project involves three offices under the FAD: the 1st Regional Office, Underwater Archaeology Division, and the Conservation Office (to be elaborated later). As of 2021, they have been working on a major excavation at the PNS site.

Archaeologists and historians interested in naval architecture will find the PNS remains an excellent source of knowledge on sewn-plank shipbuilding technology as it is one of only two sewn-plank vessels excavated in the world. As noted earlier too, the sewn-plank construction of the PNS vessel presents a shipbuilding technology that is similar to shipbuilding traditions in the Indian Ocean. And compared to the Belitung vessel, which was identified as an Arab vessel due to the use of African wood, the PNS vessel was built from Southeast Asian materials (Jumprom 2019: 226-247).

In addition to the vessel remains, the assemblage - ceramics, utensils, organic materials - are also important. Despite the small quantity of cargo remains that limits the determination of the PNS's place within the global trade network, the study of artefacts such as the ceramics still has potential to shed light on complex cultural networks. Besides, the different origins of the vessel's assemblage also hints at the origin of the crew. Persian torpedo jars (as shown in Figure 11a) on board the PNS vessel were non-cargo materials and could have been used for containing food or bitumen. One complete torpedo jar was found on the Belitung (as shown in Figure 11b), which had been erroneously identified as an amphora of Chinese origin (Chong and Murphy 2017: 268). Recent study of the PNS torpedo jars, however, reveals a substantial link with the Persian Gulf region, according to its characteristics and bitumen lining (Connan et al. 2020; Tomber, Spataro and Priestman 2020). This information suggests that some crew members onboard the PNS may have been from the western Indian Ocean or Persian Gulf. Along with the torpedo jars, Dvaravati pottery (as shown in Figures 12c and $12 \mathrm{~d}$ ) found within the assemblage also have the potential to shed light on relationships among the ancient communities on land. Chinese ceramics (as shown in Figures 12a and 12b) are part of the PNS assemblage, showing global trade links between China and the Indian Ocean world at the time. 
Conservation scientists greatly benefit from the study of the site's environmental conditions and waterlogged objects. The clay-like soil at the PNS site, geologically known as marine clay or Bangkok clay, is characteristic of the Lower Central Plain of Thailand (Teerachaikulpanich and Phupat 2003; Sinsakul 2000), where historical centres are located. The PNS site can thus help produce best-practice approaches to the conservation of sites and cultural materials in similar depositional conditions.

(a)

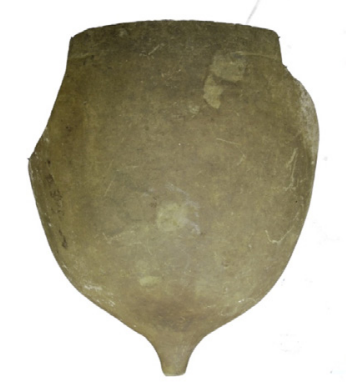

(b)

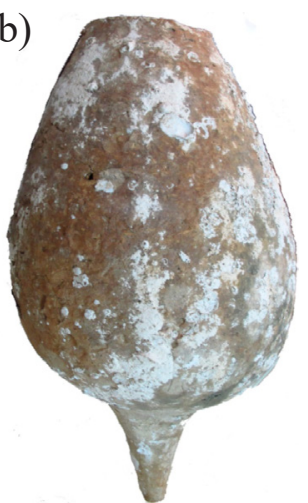

Figure 11: (a) Fragment of torpedo jar from the PNS ship at the Kanjanapisek National Museum, Thailand, and (b) Torpedo jar from the Belitung vessel (on display at Asian Civilisations Museum, Singapore; both photos courtesy of the Thai Fine Arts Department)

(a)

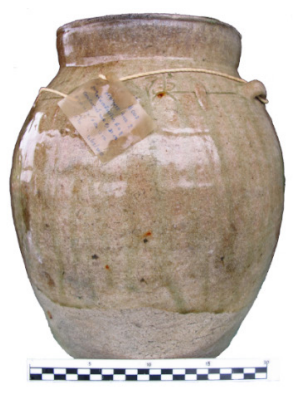

(c)

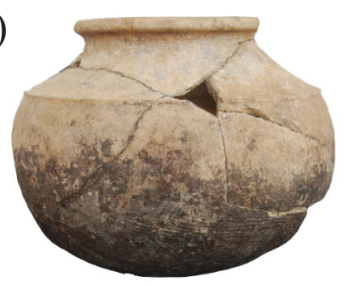

(b)

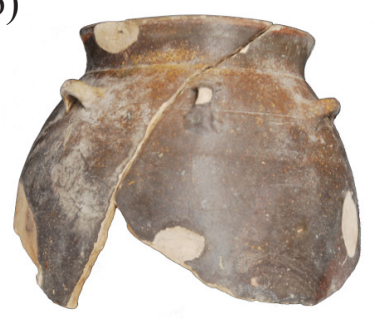

(d)

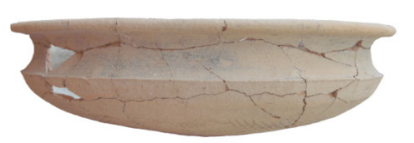

Note: Not to scale

Figure 12: Ceramics on board the PNS vessel; (a) Guangdong jar, (b) Sherds of Fengkai ware, (c) Dvaravati round-base pot and (d) Carinated bowl (photos courtesy of Thai Fine Arts Department). 
Currently, the proposed conservation plan aims to continue in-situ preservation of the majority of the structural timber. Recovered objects will be transferred to an off-site storage facility for desalination and consolidation. The scientific conservation team also experimented with a sugar-based solution on the sample timber and ropes and the results have been satisfactory. They will continue using this method on a variety of organic objects in the next phase.

\section{Political Significance}

Archaeology and politics are not easy to separate, especially in the realm of nation-state building and unification, which lead to constructs of identity (Rowlands 1994; Shanks 2004). In the 21st century, archaeology continues to provide evidence for historical relations and political cooperation. The metaphoric revival of historic route connections of the east-west corridor of the Silk Road, for example, has been used as a tool for heritage and trade diplomacy (e.g., Winter 2019: 101-133). Parallel to this, maritime cultural routes across Indian Ocean, stretching to Southeast Asia and China have been taken into international collaborative frameworks such as the Belt and Road Initiative by China in 2013 and the UNESCO (United Nations Educational, Scientific and Cultural Organization) programme on Maritime Silk Road in 2018. International support can thus be generated for the PNS site, considering its value and potential contributions to global culture. Dating back to the 9th century CE, the PNS is an important testament to the interconnections between societies prior to the emergence of Thailand as nation state. The PNS can be key evidence to define the importance of the Gulf of Thailand and mainland Southeast Asia in the long-distance trade network in the Indian Ocean World, which goes back a millennium or more. It plays a pivotal role in the context of today's globalisation by strengthening diplomatic relations between Thailand and countries found to have historical maritime connections as early as a thousand years ago.

\section{Economic Significance}

Despite its remarkable educational, scientific, cultural and political value, there is little data to evaluate the economic potential of the PNS. Realistically, the PNS site and its immediate surroundings will require a great deal of investment, such as financing by the Thai government and perhaps international organisations. One question that may be raised by 
economists is why we need to commit to a significant cost when the project would only benefit academics and politicians. The value of archaeology as cultural capital intertwined with sustainable development is a long-standing debate (Throsby 2000: 45-55). From an economic viewpoint, archaeology can be a source of income generator and economic growth through activities such as tourism and research investment (Burtenshaw 2014; Coccia 2008). A UNESCO comprehensive flyer outlines the economic value of cultural heritage in a Sustainable Development Programme (as shown in Figure 13). As the PNS site can be considered a source of economic income, it can thus be developed into an on-site museum or, optionally, set up as an education centre. It can also be placed in a cooperative trail with other nearby natural and cultural sites. But the government needs convincing. Studying and projecting its financial returns and economic benefits are therefore necessary.

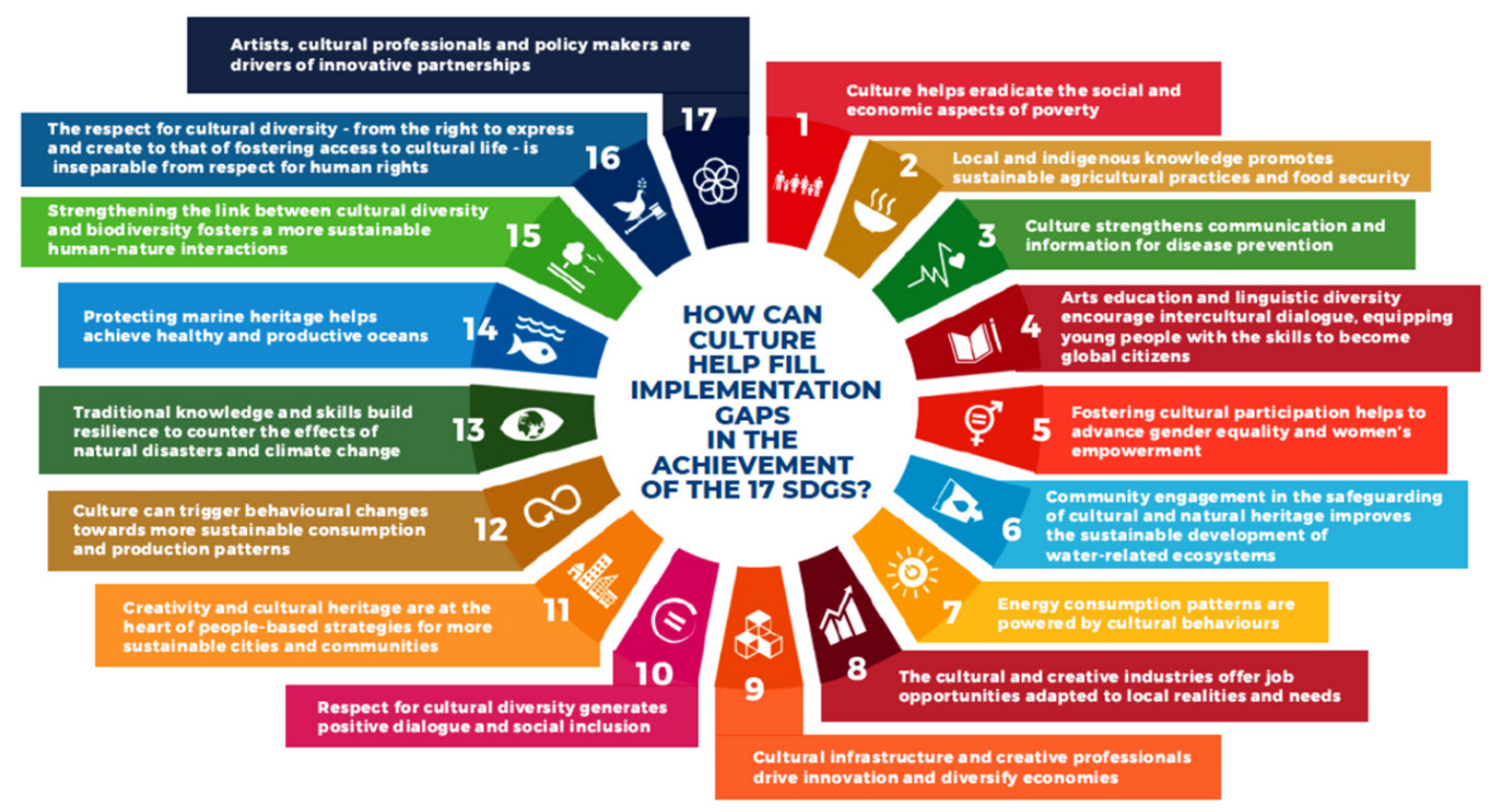

Figure 13: Diagram of Culture in the UN Sustainable Development Goals. Source: https://en.unesco.org/sustainabledevelopmentgoals

Certainly, as a tourism asset the PNS can be viewed as an indirect source of local and national income. But until this view is accepted, obtaining a budget to study, conserve and manage the site is difficult. The true value of the PNS, however, would be pointless if we only focus on its exorbitant costs and potential income. Apart from the budget it receives from the FAD, local government may contribute resources such as tools and labour assistance to the archaeological, conservation and management work on the site. The PNS has already received generous attention from locals by means 
of information sharing, donation of land and excavation facilities, among others. Such activities strongly demonstrate peoples' attachment to place, materiality and history. Taking a participatory approach as part of the sustainable development plan is crucial to gain long-term local support. It can also serve as a soft policy to avoid heritage exploitation, such as the looting and selling of artefacts; it can also help maintain the true value of such heritage.

Given the PNS' importance for global history, it can also be considered for the UNESCO World Heritage List and other international cultural programmes. International support helps increase knowledge by involving more experienced experts and relieving the financial pressure on local and national government. However, the Thai government needs to step up its efforts to highlight the PNS' significance to the international community.

\section{LEGISLATION AND APPROACHES TO ARCHAEOLOGICAL HERITAGE IN THAILAND}

This section provides an overview of the management of the archaeological heritage - which inludes underwater cultural heritage - in Thailand based on laws and practices. It includes relevant legislation, international guidelines, development of concept and organisational approach to the PNS site.

The Thai Act on Ancient Monuments, Antiques and Objects of Art and National Museum (Act 1961), amended in 1992, primarily ensures the protection of archaeological objects and sites throughout Thailand. Responsibility for the implementation of Act 1961 falls to the FAD. Archaeological materials of which no one can claim rightful ownership become state-owned property. There is no specific law granting absolute rights to the government or the FAD to automatically claim over archaeological property unless it is ownerless. Sections 14 and 24 of Act 1961 obligate the Director-General of FAD to lawfully protect the value of archaeological materials located within the sovereign territories of Thailand for the benefit of the nation. The Act 1961 extends its regulation to the sea as far as the exclusive economic zone. This legal approach implies that the FAD is the custodian of the nation's heritage rather than its representative owner.

The cultural legislation of Thailand is in line with international practices. Under the Act 1961, the definition of archaeological heritage in Thailand is based on its scientific significance (Section 4). This definition 
is consistent with that prescribed by the UNESCO and its International Committee on Monuments and Sites (ICOMOS) which also prescribes that the conservation of objects and sites of heritage significance must be based on reliable scientific methods. The latest amendment to Act 1961 in 1992 extended the scope of ancient monuments from archaeological remains to include their surroundings. The UNESCO 2001 Convention on the Protection of Underwater Cultural Heritage is consistent with the UNESCO World Heritage Convention of 1972. It explicitly stresses that archaeological and natural contexts are to be conserved together with artefacts to maintain the value of underwater cultural heritage. Although Thailand is a member state of the UNESCO 1972 convention, it does not have to follow the UNESCO 2001 standard.

In addition, the Ramsar Convention on Wetlands is worth considering along with the UNESCO conventions. The Ramsar Convention was initially designed to provide an international technical framework concerning the ecology of wetland conservation for sustainable use. Although the Ramsar Convention is not a specialised legislation for cultural heritage protection, it provides the framework for understanding the wetland conditions that are conducive to high-quality preservation for buried archaeological remains (Gearey and Chapman 2006). The occurrence of archaeology in wetland sites contributes significantly to the understanding of human past activities in the dynamic environment (Balbo, Martinez-Fernández and Esteve-Selma 2017). The location of a wetland site often links to rivers or coastal belts that can be viewed through maritime archaeological aspects (Van de Noort 2006: 34-36), as is clear with the PNS site. The archaeological character of wetlands has been increasingly discussed, particularly in Europe (Menotti 2012: 1-26). There is, therefore, a need to understand wetland archaeology within the scope of the Ramsar Convention for sustainable management of heritage sites such as that of the PNS. The integration of Ramsar Convention into the heritage dialogue has never been explicitly considered in Thailand, although there are numerous wetland resources. The discussion needs to be raised along with legal experts, scientists and authorities for the integrated future of archaeology in the wetland environment.

The concept of managing cultural heritage has for a long time existed in Thai society (Lertcharnrit 2014: 7287-7293). Early on, it was closely associated with maintaining religious buildings. This later expanded to include secular built heritage. The concept has gone through periods of change influenced by socio-political, cultural and global impact and influences (Lertrit 2000; Suteerattanapirom 2006). In recent years, the 
movement of rights-based management of culture and heritage has been increasingly debated in the global heritage community and in Thailand, with primary consideration given to the people and environment in heritage conservation. Rights to culture are guaranteed by the Constitution of Thailand (Section 43). The Constitution promotes co-management practices between the community and State Agencies but there is an ambiguity in the implementation of the law as the definitions of community and common rights to heritage have never been formalised (Sribuaiam 2019). The lack of enforceable laws creates a visible gap in the management of cultural heritage where the local people are the key stakeholder.

The management of archaeological heritage under the FAD allows some degree of involvement from other organisations, as well as the private sector. The Southeast Asian Ministers of Education Organisation-Special Program for Archaeology and the Fine Arts (SEAMEO-SPAFA) is one such organisation. SEAMEO-SPAFA is a cooperative regional organisation in charge of the professionalisation and promotion of archaeology and fine arts in Southeast Asia. It is based in Bangkok and supported by the Thai Ministry of Education. SEAMEO-SPAFA has an active role in collaboration and capacity building in related activities. Other organisations include public universities that have Archaeology programmes, including Silpakorn University, Thammasat University, Chiang Mai University and Khon Kaen University.

Despite all government and authority-based approaches to heritage management efforts in Thailand, public involvement in archaeology is still limited. There are a few community-based projects such as the Pong Manao prehistoric site in Lopburi province, the historic ceramic production in Nan province and the Pang Mapha prehistoric rock shelter in Mae Hong Son province (Natapintu 2007; Prishanchit 2005; Shoocongdej 2011). These projects have been led by renown scholars in Thailand and developed along with the local community. Samed Ngam vessel museum in Chanthaburi for instance has been administered by the local government but actual local participation still needs to be encouraged. Public involvement was active at the PNS site in 2013 (as shown in Figure 14), but has ceased since the government project was put on hold. Non-government groups increasingly participate by linking academia and the public as well as by urging government action in particular critical situations. Private entities such as Muang Boran Press, Matichon and the Siam Society continuously produce publications and activities relating to archaeology, history and culture for the purpose of public education. 

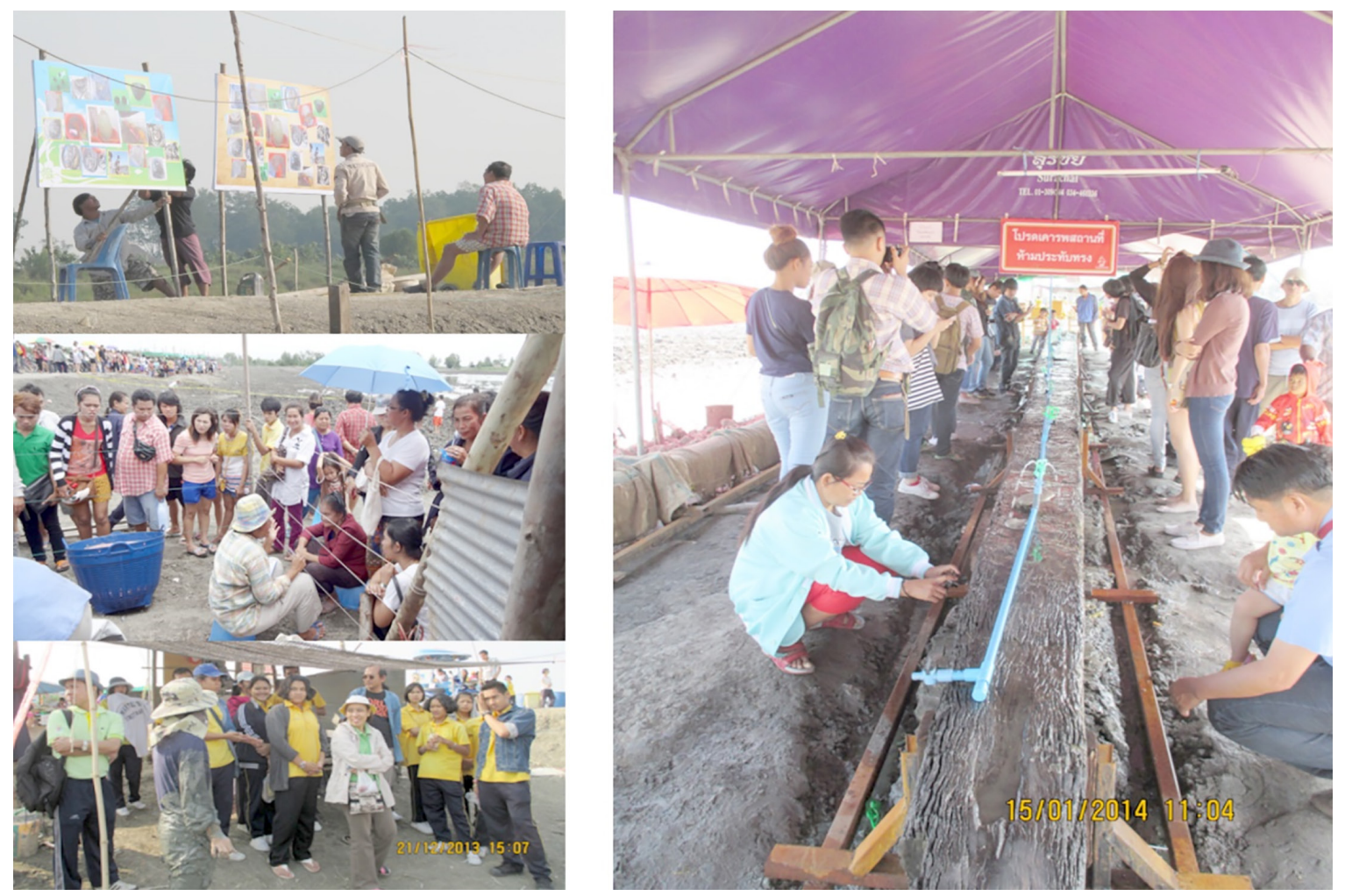

Figure 14: Public engagement at the PNS site in 2013 (photo courtesy of Thai Fine Arts Department).

There are also attempts to gain international awareness and participation. This is advocated through the global approach of UNESCO World Heritage. Universal rights to the World Heritage List are facilitated by means of archaeological heritage tourism, collaborative programmes and international funding. For foreign scholars who plan to conduct archaeological work in Thailand, this is certainly possible, but they must follow complex procedures. This involves having to directly deal with the National Research Council, Ministry of Foreign Affairs and the FAD.

In case of the PNS site, the archaeological excavation and site maintenance are managed by the FAD as stated above. Three FAD divisions have been working closely to investigate its archaeological value. The 1st Regional Office of Fine Art (Ratchaburi) is responsible for maintaining the PNS site location as well as for budgeting. The Underwater Archaeology Division under the Office of Archaeology deals primarily with archaeological sites underwater and historic shipwrecks found in Thailand's jurisdiction. Since Thailand does not have the specific legislation in dealing with the protection of the underwater heritage sites, the Division is thus a specialised office that deals with said heritage under the general legal framework. 
But the scope of responsibility should be extended to the wetland PNS site which has been submerged below ground water level for over 1,200 years. The conservation of the site is taken care of by the conservation section of the Office of National Museums.

In 2019, a Memorandum of Understanding (MoU) was signed between the FAD and three Australian institutions that include the Western Australia Maritime Museum, the University of Western Australia and Flinders University, South Australia. This MoU is aimed at developing collaborative maritime and underwater archaeology projects with priority given to the PNS site. The FAD has also reached a second agreement with the Thailand Institute of Nuclear Technology to radiometrically date archaeological materials from studied sites, including the PNS. It is hoped that the cross-institutional cooperation will increase research participation.

Along with government projects, there are also individual research projects on various aspects of the site. The first was a comparative study of the PNS shipwreck and the Belitung shipwreck by Sasichon Noothep for her undergraduate research at Silpakorn University in 2013. Then there is Sira Ploymukda's research on the formation process of the PNS site for his master's degree with Southampton University. Two current projects are also devoted to the PNS site. One is a research on Chinese ceramics by Pornnatcha Sankaprasit for her master's thesis at Flinders University and another is the author's own PhD project at the University of Western Australia, which considers the broader Indian Ocean World connections through vessel technology and selected ceramics. Moreover, an increasing number of research articles have been published by Thai and international scholars (Choksy and Nematollahi 2018; Chuenwattana, Jumprom and Komoot 2019; Connan et al. 2020; Guy 2017).

\section{CHALLENGES, CONCERNS AND CONSIDERATIONS}

Undoubtedly, the PNS shipwreck site is breaking new ground for conservation science and cultural material study in Thailand. Thus, it needs to be emphasised that careful systematic documentation of its context is crucial and distinguishes it from commercial exploitation. Given its significance and rarity, there is concern over the potential loss of information. As stated, the PNS was discovered by accident in 2013. The site has been encountering multiple challenges since the early stages, ranging from excavation techniques and wet-object conservation to 
budget allocation (Komoot 2014). To improve this situation, a systematic framework and an integrated approach are needed. As this article is written during the planning stage for the excavation in the first half of 2021, not all arrangements have been determined. These concerns are still being discussed and consulted with the authorities in charge.

The PNS site has been buried in the coastal mangrove swamp, below the water table, and was accidentally exposed during the rehabilitation of aquatic farming in 2013. An archaeological investigation was conducted by the FAD soon after its discovery. Working on a well-preserved waterlogged site tends to be much more difficult and expensive than on dry sites (Brunning 2013). High quality preservation at the same time means a lot of materials have survived and a large amount of work is needed. There are opportunities for preservation and challenges for excavation. In response to the challenges of working on the PNS site, a Rescue Archaeology was conducted. Archaeology volunteers and amateur enthusiasts were gathered to work alongside the government's team in 2013-2014. It seemed reasonable at the time, especially considering time and budget constraints, but the drawback of this approach was the difficulty in gathering detailed data from the site. Especially for a wetland site like the PNS, excavation requires different methods, equipment and skills. The proposed plan for the 2021 excavation is thus to incorporate some mapping technologyGeographical Information Systems (GIS) and 3-dimensional (3D) scan-to assist data collection along with traditional recording. Conservation has a role during this planning stage alongside the archaeology.

Challenges during excavation are multiple and include the following:

1. Conservation and maintenance are long-term commitments. Having well-trained and committed personnel is a major concern, especially regarding handling non-renewable heritage.

2. Safety is needed for archaeological crews. Working in mud can be the cause of injury, such as stepping on sharp debris, twisting ankles, or developing back pain as a result of working from awkward positions. Water circulation in the site is so poor that there is also a high chance of bacterial and fungi diseases.

3. Due to the challenging environment, the work goals need to be realistic. We must keep in mind that wetland archaeology is an unfamiliar condition for most archaeologists in Thailand and the work will proceed more slowly than usual due to the hazards and difficulties encountered on site. 
This unfamiliarity has resulted in gaps in the practical guidelines and legal framework in Thailand. Not only is the concern for the archaeological work, there is also much concern at the policy-making level. In practice, conservation and management of ancient vessel remains have never been easy.

Other sources of support, whether locally or internationally, should be considered as an option. But the COVID-19 pandemic has affected local and international support. International cooperation during this challenging time may have to remain at the remote and online platform and this is certainly a concern in managing the PNS site.

The FAD as the primary institution is mandated to oversee the study, conservation and management of the PNS site and its archaeology. Ideally, long-term planning and adequate funding for the PNS project must be prepared before proceeding with work. Currently, the overall budget allocation from the national government is small relative to the country's rich heritage and heritage tourism potential. From the total national budget of USD101 billion (THB3.2 trillion) in 2020, the FAD received a budget allocation of USD79 million (THB2.5 billion). Of this budget, $40 \%$ is allocated for integrated development projects, such as renovation and maintenance of historical buildings for tourism, capacity-building programmes and promoting campaigns. Archaeology and research projects receive only a small share. The PNS site, in particular, was allotted about USD89,000 (THB2.8 million) for all projects in 2021, which is a substantially reduced sum from the initial USD390,000 proposal for archaeology, conservation and other supplies to maintain the site.

The budget reflects the limited interest of the government in supporting archaeological projects. One concern of the authority-based approach to archaeological heritage in Thailand is the disproportionate allotment of responsibility and finances. It is however difficult to convince policymakers to provide the funds when the site is still buried under mud. This has always been a catch-22 situation for liberal policy frameworks: There can be no research progress without funding, but with no results to show there is no way to convince funders to provide institutional and research support.

The funding situation will worsen throughout the COVID-19 pandemic and global economic recession. The World Bank has predicted Thailand's export value to decline by $6.3 \%$ in 2020 , meaning that the country will gain less income. At the same time, the fiscal budget will be redirected to help relieve those affected by COVID-19 and the long-standing problems of 
poverty. As is often the case, archaeology is not the government's priority and less funding can certainly be expected in the coming years.

There are also issues at the conceptual level. As explained earlier, the surrounding archaeological context possesses irreplaceable information for the understanding and interpretation of cultural heritage. However, the determination of "surrounding" in the Act 1961 needs further discussion, based on case-by-case interpretation. Archaeologically, a site's context is not only the space that surrounds the site, but also the information associated with it that helps archaeologists reconstruct and understand the past. The issue is how to define physical heritage boundaries when socio-cultural lines are not always clear. Neither have the ecological and environmental aspects of the site been given much consideration. The PNS site location is not among the 15 wetland ecological sites in Thailand determined by the Ramsar Convention (https://www.ramsar.org/wetland/thailand). But it is worth discussing the site's ecology as part of further planning toward developing strategic approaches to the study, conservation and management of the site.

Archaeological excavation is essentially a destructive process. Failure to properly record details devalues its heritage potential. This is a valid concern for the future of the PNS site. It is hoped that history does not repeat itself and follow the same unfortunate path taken by the Belitung vessel. Despite its historical significance, debates have raged over the Belitung. The commercial salvage work and documentation conducted on it have been questioned as its context was destroyed prior to detailed environmental and archaeological study (Coleman 2013). "Commercial exploitation" as broadly defined in the UNESCO 2001 Convention is not exclusively the activities of private enterprise. Tourism, for instance, is the commercial exploitation of a site or object and this should be clarified in state praxis (Dromgoole 2013; Komoot 2011). If a site's or object's context is protected from commercial exploitation, should it be guarded too from exceedingly destructive research work? This question should be raised along with a carefully crafted research plan.

At the global level, the UNESCO 2001 Convention has set standards for the international community to practice in situ conservation work as a preferred option for managing underwater cultural heritage sites (Manders 2012). In their recommendation, a site should be protected and stabilised in its environment until facilities and resources are available to conduct proper investigations. But, at the same time, this limits public access. Different site management approaches may however be applied to different situations 
(Khakzad and Van Balen 2012). For prestigious sites, specialist intervention may be considered to gain better knowledge. Successful outcomes of such interventions are exemplified in sites such as the Batavia in Western Australia, Mary Rose in the UK, Vasa in Sweden and Nanhai No.1 in China. These sites were however all removed and managed outside of their original contexts.

The management of the PNS site is at the crossroad where the government will soon have to decide on the most feasible long-term conservation and exhibition plans. Excavation is planned for 2021 and the project design is still ongoing at the time this article is being written. I am only able to raise some general concerns with regard to the research plan, material treatment and public access. The UNESCO 2001 operational guidelines on the management activities at underwater heritage sites can be adopted for the PNS project proposal and future maritime heritage projects (Maarleveld, Guerin and Egger 2013). When considering site removal, clear research objectives and sufficient and proper resources are important, and should be clarified with the excavation team. Post-excavation processing that includes monitoring, storing and displaying the site for public consumption is also important to the conservation plans for the site and its cultural materials.

Organisational issues are caused by an outdated legal framework. Current heritage management in Thailand still follows an authority-based approach within the State Property Regime. The FAD is the designated operator in charge of scientific research and the regulator of ethical and standard practice. This is a disruptive system because the quality of research will be evaluated within its own institution and bias is likely. In academia, scientific research is assessed by external and blind peer reviewers and quality management (Lentsch and Weingart 2011, 3-4). In addition, the FAD holds too much of the workload while their resources are limited. Dr. Montira Unakul, the UNESCO senior cultural specialist, raised this issue during her talk at the Virtual Roundtables on Asian Law Series, organised by National University of Singapore on the 7th October 2020. She suggested that the FAD should consider repositioning themselves as a cultural agency that takes care of regulatory and consultancy tasks. This approach is different from outsourcing archaeological excavation with the FAD acting as an employer. Instead of relying on the government-based exercise, the FAD may reconsider its role as a provider of guidelines, administrative framework and resources for the undertaking of archaeological projects. This idea will allow professionalism (i.e. universities, research institutes 
and independent researchers) to better integrate into the archaeological heritage development. Dr Montira's suggested approach to the decentralisation of scientific research should be considered for the wellbeing of cultural heritage and the improvement of transparency in the future. Furthermore, the deeper integration of specialist public, such as museums, universities and NGOs, into archaeological research should be encouraged. For an archaeological site with global significance such as the PNS site, there is a need for a firm commitment from the central government on funding and for international communication to ensure the best practices along with public engagement. But changing in-place system needs consistent and persistent persuasion, not to mention a series of discussions to take place among the stakeholders.

Within the current framework, however, the local governments and public have minimal participation in the process of heritage management. At the very least, the general public's responsibility is not to disturb or commit any action that devalues the heritage. Damaging heritage in Thailand is a civil crime and punishable by law. The existing cultural heritage legislation, Act 1961, was designed to provide protection to the cultural heritage and encourage heritage stakeholders' participation. As such both the current laws and the government's attitude should be reviewed. Global conversations may influence national debates but they normally take a long time to influence those tasked to implement the Thai laws.

\section{FUTURE OF THE PNS SITE}

The PNS site is very important locally, regionally and globally, and demands special care as it can to generate knowledge and understanding of the past. Diverse disciplines are thus needed to open opportunities for research collaboration and mutual understanding among partners. Hopefully what the PNS might give back to the nation and community in terms of public education, strengthened diplomatic ties and developed maritime cultural partnerships with countries along the Indian Ocean littoral should be factored in together with the income generated from the PNS visitors. The site provides unique universal cultural components that can be taken into consideration for international cooperation such as World Heritage Listing and some of the 17 UN Sustainable Development Goals for 2021-2030 (e.g., development of education and eradication of poverty). Thus, to develop the knowledge within this topic, its context must be taken seriously. More 
work is required to gain a better understanding of the PNS's past as well as achieve its full heritage potential and this work needs to be done properly. It is also important to note here that negative impacts of suggested activities, such as unethical research, commercial exploitation and political disadvantages, on the PNS site are possible but they are not the focus of this article. They are certainly worth discussing the next steps in the near future.

This article hopes to further an ongoing discussion on how we want to see the PNS site in the next 20 or more years. Do we have adequate management strategies and research plans in place? Do we have the necessary specialists and specialised technology? Another important question for the future debate that needs to be asked is regarding "who". Who should the PNS site be managed for? Is it for people in the present or the future generation, general public or a privileged group? What is the best way possible to safeguard the PNS site in its original location for the public? How should the in situ preservation be implemented within the PNS context?

The future of the PNS site requires careful evaluation and comprehensive information. Indeed, there is much knowledge to be gained where Thailand as a nation profits and the Fine Arts Department as mandated by the state has a key ethical role in steering the direction of heritage management plans for the PNS site through best practice. In seeing this successful future through the PNS site for humanity's benefit, the Thai government should call for collaboration, mutual respect and consideration for all issues raised by its stakeholders. The direction taken by the government will undoubtedly impact future practices for archaeological vessel preservation and knowledge production in Thailand.

\section{ACKNOWLEDGEMENT}

The author would like to extend her gratitude to the Fine Arts Department, Ms. Preeyanuch Jumprom, senior archaeologist and Ms. Guntima Tunjai, conservation scientist, for sharing their thoughts and information. Deep appreciation also goes to Dr. Martijn Manders, Dutch Cultural Agency, Dr. Bill Jeffery, University of Guam and Mr. Vito Hernandez, Flinders University for their assistance in editing and reviewing the drafts. 


\section{NOTES}

* Abhirada Komoot is a $\mathrm{PhD}$ candidate in archaeology at the University of Western Australia. Her current research focuses on the 9th century PNS vessel in Samut Sakhon province, Thailand. She is a passionate scholar who has diverse educational and professional backgrounds. She obtained her first degree from the Faculty of Archaeology, Silpakorn University in 2005 and began to explore knowledge in underwater archaeology during her undergraduate years. She joined the underwater archaeology training programme and volunteering work since 2004. In 2008, she expanded her interest to legal matters and pursued her other degree in law (LL.B.) at Thammasat University. Spontaneously, she was appointed as a project assistant and coordinator for UNESCO foundation courses on underwater cultural heritage in AsiaPacific regions from 2009 to 2011. After that, she secured a scholarship to continue her master's degree in archaeological heritage management at the University of Leiden, the Netherlands. Over the course of years, she has been working actively and closely with Thai government in relation to maritime and underwater cultural heritage.

1 The site is therefore called after the names of the landowners - Mrs. Phanom and Mr Surin Sri-Ngamdee.

\section{BIBLIOGRAPHY}

Balbo, A. L., Martinez-Fernández, J. and Esteve-Selma, M. -A. 2017. Mediterranean wetlands: archaeology, ecology and sustainability. WIREs Water 4 (6): e1238. https://doi.org/10.1002/wat2.1238

Ban Khom Shipwreck. 1998. FAD1, 1stRegional Office of Fine Arts Ratchaburi(Ratchaburi). Briggs, L. P. 1950. The Khmer empire and the Malay Peninsula. The Far Eastern Quarterly 9 (3): 256-305.

Brunning, R. 2013. Archaeological strategies for terrestrial wetland landscapes. In The Oxford handbook of wetland archaeology, eds. Menotti, F. and O'Sullivan, A., 451-463. Oxford: Oxford University Press. https://doi.org/10 .1093/oxfordhb/9780199573493.013.0027

Bureau of the Budget, Thai Parliament B. E. 2663. 2020. Analysis of approved budgets for Ministry of Culture [in Thai]. https://www.parliament.go.th/ewtadmin/ewt/ parbudget/download/article/article_20191213151522.pdf.

Burtenshaw, P. 2014. Mind the gap: Cultural and economic values in archaeology. Public Archaeology 13 (1-3): 48-58. https://doi.org/10.1179/1465518714Z.00000000053

Choksy, J. K. and Nematollahi, N. 2018. The middle Persian inscription from a shipwreck in Thailand: Merchants, containers and commodities. Dabir 6: 144-150.

Chong, A. and Murphy, S. A., eds. 2017. The Tang shipwreck: Art and exchange in the 9th century. Singapore: Asian Civilisations Museum.

Chuenwattana, N., Jumprom, P. and Komoot, A. 2019. Forest goods, rice and betel nut: Preliminary archaeobotanical analysis from Phanom-Surin shipwreck, Samut Sakhon province, Thailand. Silpakorn Journal 62 (4): 65-79. 
Coccia, M. 2008. Science, funding and economic growth: Analysis and science policy implications. World Review of Science, Technology and Sustainable Development 5 (1): 1-27. https://doi.org/10.1504/wrstsd.2008.01781

Coleman, P. 2013. UNESCO and the Belitung shipwreck: The need for a permissive definition of commercial exploitation. George Washington International Law Review 45 (4): 847-874.

Connan, J. et al. 2020. Geochemical analysis of bitumen from West Asian torpedo jars from the c. 8th century Phanom-Surin shipwreck in Thailand. Journal of Archaeological Science 117: 105111. https://doi.org/https://doi.org/10.1016/j.jas.2020.105111

Dromgoole, S. 2013. Underwater cultural heritage and international law. New York: Cambridge University Press.

Dupont, P. 2006. The archaeology of the Mons of Dvāravatī. Edited by J. K. Sen. Bangkok: White Lotus Press.

Flecker, M. 2000. A 9th-century Arab or Indian shipwreck in Indonesian waters. The International Journal of Nautical Archaeology 29 (2): 199-217. https://doi .org/http://dx.doi.org/10.1006/ijna.2000.0316

Gearey, B. R. and Chapman, H. P. 2006. Planning policy, in situ preservation and wetland archaeology in the United Kingdom: Some present concerns. Conservation and Management of Archaeological Sites 7 (3): 179-182. https://doi .org/10.1179/135050306793137421

Government of Thailand. 1961. Act on ancient monuments, antiques and objects of art and national museum, B.E. 2504, of 1961 (as amended 1992) [in Thai]. https://www.m-culture.go.th/mculture_th60/article_attach/28.pdf.

Guy, J. 2017. The Phanom Surin shipwreck, a Pahlavi inscription and their significance for the history of early lower central Thailand. Journal of the Siam Society 105: 179-196.

Hutangkura, T. 2014. Reconsidering the Palaeo-shoreline in the Lower Central Plain of Thailand. In Before Siam. Essays in art and archaeology, eds. Revire, N. and Murphy, S., 32-67. Bangkok: River Books and The Siam Society.

Jumprom, P. 2019. Recovery of a Lost Arab-styled Ship at Phanom-Surin, the wetland excavation site in Central Thailand. In Ancient maritime cross-cultural exchanges: Archaeological research in Thailand, eds. Srisuchat, A. and Giessler, W., 226-285. Bangkok: Rung Silp Printing Co. Ltd.

Khakzad, S. and Van Balen, K. 2012. Complications and effectiveness of in situ preservation methods for underwater cultural heritage sites. Conservation and Management of Archaeological Sites 14 (1-4): 469-478. https://doi.org/10.1179/135050331 2Z.00000000040.

Komoot, A. 2011. Can tourism exploitation of underwater cultural heritage (UCH) be incompatible with the UNESCO 2001 Convention? Paper presented at the AsiaPacific Regional Conference on Underwater Cultural Heritage, Manila, Philippines, 8-12 November.

. Forthcoming. Indian Ocean maritime connections of the 1st millennium CE: The study of the Phanom-Surin shipwreck in Thailand. PhD diss., University of Western Australia, Australia.. 
Krahl, R. and Effeny, A. 2010. Shipwrecked: Tang treasures and monsoon winds. In Tang treasures and monsoon windseds, Krahl, R. and Effeny, A. Washington, DC: Arthur M. Sackler Gallery, Smithsonian Institution.

Lacsina, L. 2016. Examining pre-colonial Southeast Asian boatbuilding: An archaeological study of the Butuan Boats and the use of edge-joined planking in local and regional construction techniques. PhD diss., Flinders University, Australia..

Lentsch, J. and Weingart, P. 2011. The politics of scientific advice: Institutional design for quality assurance. Cambridge, UK: Cambridge University Press.

Lertcharnrit, T. 2014. Cultural heritage management in Thailand. In Encyclopedia of global archaeology, ed. Smith, C. New York: Springer.

Lertrit, S. 2000. Cultural resource management and archaeology at Chiang Saen, Northern Thailand. Journal of Southeast Asian Studies 31 (1): 137-161.

Li, H. -L., ed. 1979. Nan-fang ts 'ao-mu chuang = A fourth century flora of Southeast Asia: Introduction, translation, commentaries/Hui-lin Li. Hong Kong: Chinese University Press.

Liebner, H. H. 2014. The siren of Cirebon: A tenth-century trading vessel lost in the Java Sea. PhD diss., University of Leeds, UK.

Maarleveld, T. J., Guerin, U. and Egger, B., eds. 2013. Manual for activities directed at underwater cultural heritage: Guidelines to the Annex of the UNESCO 2001 Convention. Paris: UNESCO.

Mackintosh-Smith, T. et al. 2014. Two Arabic travel books. New York: New York University Press.

Manders, M. 2012. In situ preservation. Bangkok: UNESCO. http://www.unesco.org/new/ fileadmin/MULTIMEDIA/HQ/CLT/images/630X300/UNIT9.pdf.

Manguin, P. 1993. Trading ships of the South China Sea: Shipbuilding techniques and their role in the history of the development of Asian trade networks. Journal of the Economic and Social History of the Orient 36 (3): 253-280. https://doi.org/ $10.2307 / 3632633$

2019. Sewn boats of Southeast Asia: The stitched-plank and lashed-lug tradition. International Journal of Nautical Archaeology 48 (2): 400-415. https://doi.org/10.1111/1095-9270.12367

Menotti, F. 2012. Wetland archaeology and beyond: Theory and practice. Oxford: Oxford University Press.

Mochtar, A. S. 2018. The seventh-century Punjulharjo boat from Indonesia: A study of the early Southeast Asian lashed-lug boatbuilding tradition. Master's diss., Flinders University, Australia.

Natapintu, S. 2007. Contribution of archaeology to the quality of life improvement at the village of Ban Pong Manao, Lopburi province, Central Thailand. In Proceedings of the international seminar on archaeology and nation building August 2005, eds. Saidin, M. and Chia, S., 22-31. Pulau Pinang, Malaysia: Universiti Sains Malaysia.

Noothep, S. 2013. Arab-style shipwrecks in Southeast Asia: A comparative study of the Belitung and Phanom-Surin ships. Undergraduate individual study, Silpakorn University, Thailand. 
Ploymukda, S. 2016. The study of the site formation process and paleoenvironment of Phanom-Surin shipwreck the 9th century shipwreck in the gulf of Thailand. Master's diss., University of Southampton, UK.

Prishanchit, S. 2005. Community archaeology: Past management and community development. Bangkok: Community Archaeology.

Ramsar. 1971. Convention on wetlands (as amended 1982 and 1987). https://www.ramsar .org/sites/default/files/documents/library/current_convention_text_e.pdf.

Rowlands, M. 1994. The politics of identity in archaeology. In Social construction of the past: Representation as power, eds. Bond, G. C. and Gilliam, A. London: Routledge.

Shanks, M. 2004. Archaeology and politics. In A companion to archaeology, eds. Bintliff, J., Earle, T. and Peebles, C. Hoboken, NJ: John Wiley \& Sons, Inc.

Shoocongdej, R. 2011. Public archaeology in Thailand. In New perspectives in global public archaeology, eds. Matsuda, A. and Okamura, K. New York: Springer.

Sinsakul, S. 2000. Late quaternary geology of the Lower Central Plain, Thailand. Journal of Asian Earth Sciences 18 (4): 415-426. https://doi.org/10.1016/s13679120(99)00075-9

Songtham, W., Musika, S., Mildenhall, D. C., Cochran, U. A. and Kojevnikova, D. 2015. Development of the Lower Central Plain of Thailand with history of human settlements: Evidence from pollen, spores and diatoms. Journal of Geological Resource and Engineering 2: 98-107. https://doi.org/10.17265/2328 $-2193 / 2015.02 .004$

Sribuaiam, K. 2019. Linkage between "community rights" and "natural resources and environment" under the Thai Constitution B.E. 2560. Ramkhamhaeng Law Journal 8 (1).

Suteerattanapirom, K. 2006. The development of concept and practice of ancient monuments conservation in Thailand. Damrong Journal: Journal of the Faculty of Archaeology 5 (2): $133-150$.

Teerachaikulpanich, N. and Phupat, V. 2003. Geological and geotechnical engineering properties of Bangkok clay. In Proceedings of the 38th international conference on geotechnical engineering, Japan, 143-144. Tokyo: The Japanese Geotechnical Society. https://doi.org/10.11512/jiban.JGS38.0.143.0

Throsby, D. 2000. Economics and culture. Cambridge, UK: Cambridge University Press.

Tomber, R., Spataro, M. and Priestman, S. 2020. Early Islamic torpedo jars from Siraf: Scientific Analyses of the clay fabric and source of Indian Ocean transport containers. Iran: Journal of the British Institute of Persian Studies 1-24. https://doi.org/10.1080/05786967.2020.1792797.

UNESCO (United Nations Educational, Scientific and Cultural Organization). 1972. World heritage convention. https://whc.unesco.org/en/conventiontext/.

2001. The convention on the protection of the underwater cultural heritage. http://www.unesco.org/new/en/culture/themes/underwater-cultural-heritage/2001 -convention/official-text/.

Van de Noort, R. 2006. Rethinking wetland archaeology. In Duckworth debates in archaeology, ed. O’Sullivan, A. London: Duckworth. 
Wales, H. G. Q. 1969. Dvaravati: The earliest kingdom of Siam; (6th to 11th century A.D.). London: Quartich.

Winter, Tim. 2019. Geocultural power: China's quest to revive the Silk Roads for the twenty-first century. Chicago: University of Chicago Press.

Zhaoming, X. 2014. The Hepu Han tombs and the maritime Silk Road of the Han Dynasty. Antiquity 88 (342): 1229-1243. https://doi.org/10.1017/S0003598X0011542X 